\title{
Improving the Performance of Fixed-Bed Catalytic Reactors by Innovative Catalyst Distribution
}

\author{
Violeta Alejandra Chichique Martínez ${ }^{1,2}$, Farhang Shadman ${ }^{1}$ \\ ${ }^{1}$ Department of Chemical and Environmental Engineering, University of Arizona, Tucson, AZ, USA \\ ${ }^{2}$ Departamento de Ingeniería de Procesos y Ciencias Ambientales, Universidad Centroamericana “José Simeón Cañas” (UCA), \\ San Salvador, El Salvador \\ Email: shadman@erc.arizona.edu
}

How to cite this paper: Martínez, V.A.C. and Shadman, F. (2020) Improving the Performance of Fixed-Bed Catalytic Reactors by Innovative Catalyst Distribution. Journal of Applied Mathematics and Physics, 8, 672-683.

https://doi.org/10.4236/jamp.2020.84052

Received: March 6, 2020

Accepted: April 6, 2020

Published: April 9, 2020

Copyright $\odot 2020$ by author(s) and Scientific Research Publishing Inc. This work is licensed under the Creative Commons Attribution International License (CC BY 4.0).

http://creativecommons.org/licenses/by/4.0/

\begin{abstract}
A comprehensive mathematical model is developed to simulate the interactions of the complex processes that take place in typical catalytic chemical reactors. This mathematical model includes correlations representing various modes of mass transport and chemical reactions. To illustrate the application and value of this approach for reactor optimizations, the model is applied to the case of series reactions with a desirable intermediate compound and the risk of degradation of this compound if the process conditions are not optimized. The modeling results show that in such cases, which are very common in practice, replacing the conventional uniform catalyst distribution with a novel non-uniform distribution will significantly improve the performance of the reactor and the production of the desirable compound. Various catalyst distribution options are compared, and a novel non-uniform loading of catalyst is identified that gives a much better performance compared to the conventional approach. The model is versatile and useful for both the design as well as the optimization of the catalytic fixed-bed reactors in a wide variety of reactor and reaction conditions.
\end{abstract}

\section{Keywords}

Catalyst, Reactor Optimization, Series Reactions, Uniform Catalyst

Distribution, Non-Uniform Catalyst Distribution, Catalyst Deactivation

\section{Introduction}

Many industrial catalytic processes involve multiple reactions, often in the form of a series of steps in which an intermediate compound in the series is the prod- 
uct of interest. In these reactor systems, the maximum conversion of the feed compound is not necessarily the best design or operation; instead, there is a certain level or range of conversion of the primary feed that gives the optimum yield of the desired product and often the best catalyst life and performance [1]. If the conversion exceeds this optimum level, the desired product degrades into undesirable end-products, which will reduce the quality of the overall reactor output. Moreover, these undesirable compounds often adsorb on the catalyst surface and deactivate it by various mechanisms [2].

Among examples of these series reactions with desired intermediate products are hydrogenation [3], dehydrogenation [4], cracking, alkylation, isomerization, and reforming involving organic molecules, with applications in petroleum refining, fuel production, and petrochemical industry. In dehydrogenation and cracking, the desired compound is typically a partially unsaturated intermediate which is formed from a more saturated starting molecule by formation of some double or triple carbon-carbon bonds [5] [6] [7]. The importance of selectivity in multiple reactions has been the subject of numerous studies and is available in research publications and reviews [8] [9]. If the dehydrogenation goes too far, the conversion will fall out of desired range, and even worse will result in the formation of heavy tar-like molecules that deactivate the catalyst by adsorption on the catalytic sites (poisoning) or by plugging the pores and decreasing the catalytically active area (coking and fouling) [6] [7].

Reaction time is the main parameter determining the extent of reaction for these cases. Consequently, the degree of conversion is primarily controlled by adjusting the residence time in the batch or mixed reactors (such as fluidized-bed). In the fixed-bed reactors, in addition to the residence time, other design and operation control options become available due to the spatial variation of concentration and reaction rates along the reactor bed. The idea behind this research is to use this spatial variation option and explore potential advantages of non-uniform catalyst distribution in the fixed-bed reactors. Therefore, the focus has been on the development and unitization of a methodology that would allow parametric analysis and evaluation of various catalyst activity distributions in the fixed-bed reactors. To achieve this, the methodology needs to be robust and flexible to allow considering and evaluating a wide range of reactor and reaction properties. Additionally, the intended analysis method should provide information about the effect of these non-conventional new catalyst distribution schemes on the deactivation and the life of the catalyst.

\section{Method of Approach}

The method of approach adopted for this study has been to develop a comprehensive and yet versatile process model for fixed bed catalytic reactors running typical series reactions with desirable intermediate products, and undesirable and potentially deactivating end products. In the first part, the fundamental mass conservation methodology and correlations [10] were used to formulate 
the governing process model equations; these equations included parameters representing the reactor and reaction properties. The formulation is applicable to a wide variety of cases and would be a good general approach to evaluate the potential merits of the non-uniform catalyst distribution. To solve these inter-dependent equations, several numerical methods were tested and compared to find a robust and reliable method. To assure the accuracy of the numerical method, the formulation was tested by solving and comparing the temporal concentration profiles, using several solvers as well as those obtained by analytical solutions possible for the limiting cases. In the second part, the validated model was used in a parametric study to compare the reactor performance, indicated by the species concentrations and the production rate of the desirable compound for conventional (uniform) and unconventional (non-uniform) catalyst distribution cases. Finally, in the third part of the study, the effect of catalyst deactivation for both uniform and non-uniform catalyst distribution cases was analyzed.

Specific intended results for this process modeling include: 1) determining the concentration profiles of all compounds participating in the process, the production rate of the desirable compounds and the variation of these key properties with time and location in the reactor; 2) quantifying the potential formation and deposition of the undesirable compounds on the catalyst surface and the effect on the performance of the reactor over time.

\section{Process Model Description}

The simplified schematic of a typical fixed-bed reactor and the process steps occurring in it are shown in Figure 1. The fluid phase reactions take place over the catalytic packing that fills the reactor. The reaction sequence considered for this study consists of a series of two reversible reactions as depicted in Equation (1) and Equation (2):

$$
\begin{aligned}
& A_{(g)} \leftrightarrow R_{(g)} \\
& R_{(g)} \leftrightarrow S_{(g)}
\end{aligned}
$$

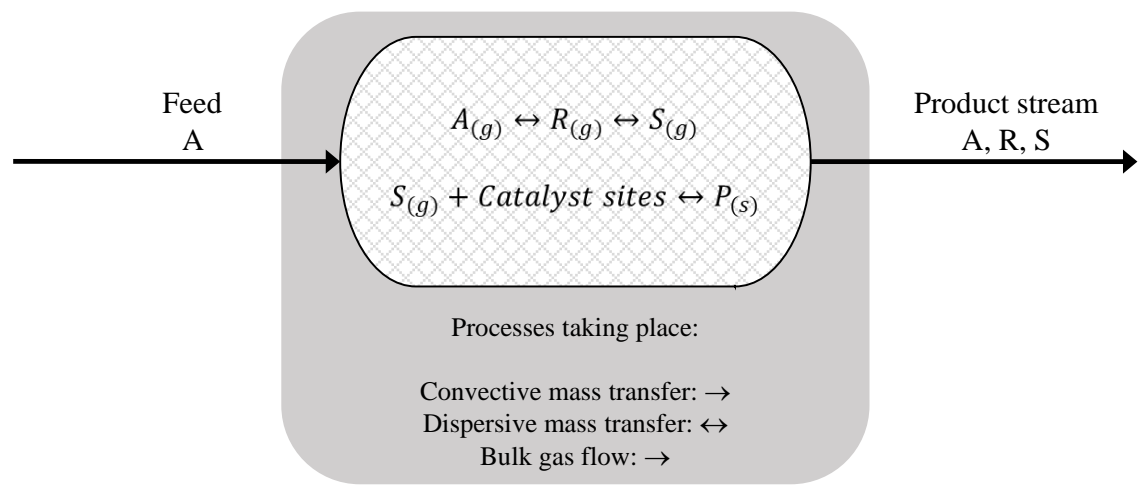

Figure 1. Schematic of the fixed-bed reactor and the key process steps: convective mass transfer, dispersive mass transfer, and bulk gas flow. 
In the first reaction, the transformation of $A$ yields the compound of interest, $R$. However, $R$ can degrade by further non-catalytic reaction to an undesirable compound, $S$. To include the potential catalytic deactivation, typically observed in these series reactions, further transformation of $S$ is included to represent the formation and deposition of a condensed species $P$ on the catalyst surface; this deactivation reaction is shown by Equation (3):

$$
S_{(g)} \leftrightarrow P_{(s)}
$$

The model includes convective and dispersive mass transfer steps in both bulk fluid and through the catalytic packed bed in addition to these reactions.

The rates of formation and consumption of the above species are given by Equations (4) to (7). For the fluid-phase compounds $A, R$, and $S$, the concentrations $\left(C_{A}, C_{R}\right.$, and $\left.C_{S}\right)$ are in $\mathrm{mol} / \mathrm{m}^{3}$ and the rates are in $\mathrm{mol} / \mathrm{m}^{3} \cdot \mathrm{s}$. For the condensed compound $P$, the rate is in $\mathrm{mol} / \mathrm{m}^{2} \cdot \mathrm{s}$. All reactions are assumed to be first order with respect to the reacting species. However, when catalyst sites are involved in the reaction, the reaction rate also depends and is proportional to the number of available catalytic sites $\left(Z-C_{P}\right)$; this is the case for the main reaction of $A$ going to $R$ and its reverse as well as the deactivation reaction of $S$ going to $P$. In this expression, $Z$ is the surface concentration of active catalytic sites and $C_{P}$ is the surface concentration of deactivated sites occupied by compound $P$. Both $Z$ and $C_{P}$ vary with time and location in the reactor and are in units of $\mathrm{mol} / \mathrm{m}^{2}$. In these equations, a represents the ratio of the catalytic surface area to the volume of the reactor in $\mathrm{m}^{-1}$. The intrinsic reaction rate constants are in units of $\mathrm{m}^{2} / \mathrm{mol} \cdot \mathrm{s}$ for $k_{1}, k_{1 r}$ and $k_{3}$; and $\mathrm{s}^{-1}$ for $k_{2}, k_{2 r}$ and $k_{3 r}$

$$
\text { Net rate of production of } A=-k_{1} C_{A}\left(Z-C_{P}\right)+k_{1 r} C_{R}\left(Z-C_{P}\right)
$$

Net rate of production of $R=k_{1} C_{A}\left(Z-C_{P}\right)-k_{1 r} C_{R}\left(Z-C_{P}\right)-k_{2} C_{R}+k_{2 r} C_{S}$

$$
\text { Net rate of production of } S=k_{2} C_{R}-k_{2 r} C_{S}-k_{3} C_{S}\left(Z-C_{P}\right)+a k_{3 r} C_{P}
$$

$$
\text { Net rate of production of } P=\frac{1}{a} k_{3} C_{s}\left(Z-C_{P}\right)-k_{3 r} C_{P}
$$

The transport of species in the fluid phase by both convection and dispersion were included in the model. Considering the above steps, Equations (8) to (11) are derived to represent the mass balance for participating compounds and their variation with time, $t$, and location along the packed bed, $x$. For the following expressions, $v$ is the velocity of the fluid in $\mathrm{m} / \mathrm{s}$, and $D_{i}$ is the dispersion coefficient for compound $i$ in $\mathrm{m}^{2} / \mathrm{s}$.

$$
\begin{gathered}
\frac{\partial C_{A}}{\partial t}-D_{A} \frac{\partial^{2} C_{A}}{\partial x^{2}}+v \frac{\partial C_{A}}{\partial x}=-k_{1} C_{A}\left(Z-C_{P}\right)+k_{1 r} C_{R}\left(Z-C_{P}\right) \\
\frac{\partial C_{R}}{\partial t}-D_{R} \frac{\partial^{2} C_{R}}{\partial x^{2}}+v \frac{\partial C_{R}}{\partial x}=k_{1} C_{A}\left(Z-C_{P}\right)-k_{1 r} C_{R}\left(Z-C_{P}\right)-k_{2} C_{R}+k_{2 r} C_{S} \\
\frac{\partial C_{S}}{\partial t}-D_{S} \frac{\partial^{2} C_{S}}{\partial x^{2}}+v \frac{\partial C_{S}}{\partial x}=k_{2} C_{R}-k_{2 r} C_{S}-k_{3} C_{S}\left(Z-C_{P}\right)+a k_{3 r} C_{P} \\
\frac{\partial C_{P}}{\partial t}=\frac{1}{a} k_{3} C_{S}\left(Z-C_{P}\right)-k_{3 r} C_{p}
\end{gathered}
$$


The boundary conditions for the inlet $(x=0)$ and the outlet $(x=L)$ are described in Equation (12) and Equation (13), whereas the initial conditions used for all cases are shown in Equation (14). In these expressions, $L$ is the length of the reactor in $\mathrm{m}$; and $C_{i, o}, C_{i, i n}$, and $C_{i}$ are the inlet concentrations of species $i$ in the reactor feed, the initial concentrations of species $i(t=0)$ and the concentrations of species $i$, respectively, all of them in $\mathrm{mol} / \mathrm{m}^{3}$.

$$
\begin{gathered}
v \cdot C_{i, o}=v \cdot C_{i}-D_{i} \cdot \frac{\mathrm{d} C_{i}}{\mathrm{~d} x} \text { at } x=0 \\
\frac{\mathrm{d} C_{i}}{\mathrm{~d} x}=0 \text { at } x=L \\
C_{i}=C_{i, i n} \text { at } t=0
\end{gathered}
$$

Among the key performance indicators for the reactor are the net consumption and net production rates of various species, and the cumulative conversion of reactant. Similarly, the total poison at any time over the length of the reactor is proposed to describe the deactivation process. The general equations for these indicators are given by Equations (15) to (18). In these expressions, $C_{i, \text { out }}$ is the concentration of that species at the outlet in $\mathrm{mol} / \mathrm{m}^{3}$, and $d$ is the diameter of the reactor in $m$.

$$
\begin{aligned}
& \text { Net rate of production of } i=\pi \cdot \frac{d^{2}}{4} \cdot v \cdot\left(C_{i, \text { out }}-C_{i, o}\right) \\
& \text { Net rate of consumption of } i=\pi \cdot \frac{d^{2}}{4} \cdot v \cdot\left(C_{i, o}-C_{i, \text { out }}\right) \\
& \text { Comulative conversion }=\int_{0}^{t} \pi \cdot \frac{d^{2}}{4} \cdot v \cdot\left(C_{i, o}-C_{i}\right) \mathrm{d} t \\
& \text { Total poison }=\int_{0}^{L} C_{p} \cdot a \cdot \pi \cdot \frac{d^{2}}{4} \mathrm{~d} x
\end{aligned}
$$

To allow a comprehensive study of the non-uniform catalyst distribution option in the model, the initial distribution of catalyst in the reactor, $Z$, is considered a function of location in the reactor. This parameter represents the starting property of catalyst loading in the reactor before deactivation. Figure 2 shows the various distributions that were considered and evaluated in this study as well as the equations that describe each case. In the expressions depicted in Figure 2, $m$ is a parameter in the catalyst distribution equation ranging from zero to one $(0<m<1)$, and $Z_{o}$ is the value of $Z$ for the uniform distribution. The total amount of catalyst was the same in all the distributions tested.

A parametric case study was performed to compare potential options for catalyst distribution, using profiles shown in Figure 2 and a set of parameters listed in Table 1. Since the focus of this modeling is not just a particular chemistry case or set of reactions, the work should be considered a generic study, using parameters in practical range to illustrate the trends and potential merits of the unconventional non-uniform distribution. This parametric study also illustrates the robustness and applicability of the model for a wide variety of situations and reacting systems. 
a)

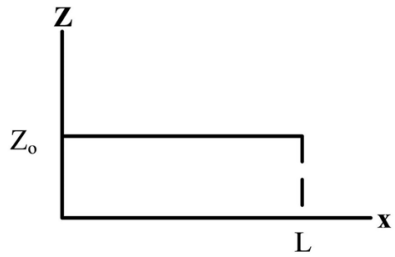

Uniform distribution

b)

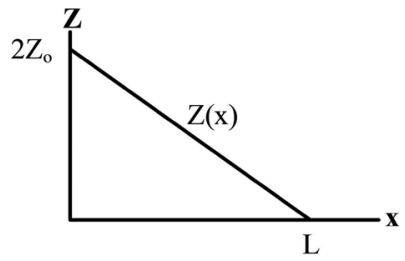

$$
m=0 \text { and } Z=-\frac{2 Z_{o}}{L} \cdot x+2 Z_{o}
$$

c)

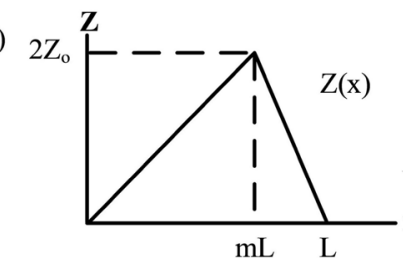

$$
\begin{gathered}
0<x<m L \text { and } Z=\frac{2 Z_{o}}{m L} \cdot x \\
m L<x<L \text { and } Z=-\frac{2 Z_{o}}{(1-m) L} \cdot x+\frac{2 Z_{o}}{1-m}
\end{gathered}
$$

d)

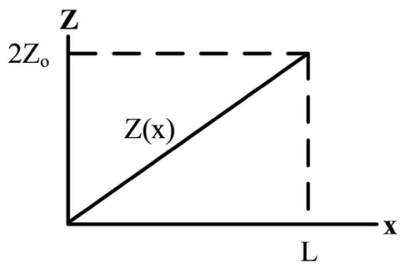

$$
m=1 \text { and } Z=\frac{2 Z_{o}}{L} \cdot x
$$

Figure 2. Catalyst distributions considered in this study: (a) uniform distribution; (b)

\begin{tabular}{|c|c|c|}
\hline Parameter & Variable & Value \\
\hline Catalytic surface area divided by reactor volume & $a$ & $1000 \mathrm{~m}^{-1}$ \\
\hline Concentration of compound $i$ in reactor feed & $C_{i, o}$ & $\begin{aligned} C_{A, o} & =20 \mathrm{~mol} / \mathrm{m}^{3} \\
C_{R, o} & =0 \mathrm{~mol} / \mathrm{m}^{3} \\
C_{S, o} & =0 \mathrm{~mol} / \mathrm{m}^{3} \\
C_{P, o} & =0 \mathrm{~mol} / \mathrm{m}^{3}\end{aligned}$ \\
\hline Initial concentration of compound $i$ & $C_{i, i n}$ & $\begin{aligned} C_{A, \text { in }} & =20 \mathrm{~mol} / \mathrm{m}^{3} \\
C_{R, \text { in }} & =0 \mathrm{~mol} / \mathrm{m}^{3} \\
C_{S, \text { in }} & =0 \mathrm{~mol} / \mathrm{m}^{3} \\
C_{P, \text { in }} & =0 \mathrm{~mol} / \mathrm{m}^{2}\end{aligned}$ \\
\hline Dispersion coefficient of compound $i$ & $D_{i}$ & $\begin{aligned} D_{A} & =1 \times 10^{-7} \mathrm{~m}^{2} / \mathrm{s} \\
D_{R} & =1 \times 10^{-7} \mathrm{~m}^{2} / \mathrm{s} \\
D_{S} & =1 \times 10^{-7} \mathrm{~m}^{2} / \mathrm{s}\end{aligned}$ \\
\hline Forward reaction rate coefficient of compound $i$ & $k_{i}$ & $\begin{array}{c}k_{1}=4 \times 10^{-1} \mathrm{~m}^{2} / \mathrm{mol} \cdot \mathrm{s} \\
k_{2}=1 \times 10^{-2} \mathrm{~s}^{-1} \\
k_{3}=4 \mathrm{~m}^{2} / \mathrm{mol} \cdot \mathrm{s}\end{array}$ \\
\hline Reverse reaction rate coefficient of compound $i$ & $k_{i r}$ & $\begin{array}{c}k_{I}=1 \times 10^{-3} \mathrm{~m}^{2} / \mathrm{mol} \cdot \mathrm{s} \\
k_{2 r}=0 \mathrm{~s}^{-1} \\
k_{3 r}=0 \mathrm{~s}^{-1}\end{array}$ \\
\hline
\end{tabular}
non-uniform distribution $(m=0)$; (c) non-uniform distribution $(0<m<1)$; (d) non-uniform distribution $(m=1)$.

Table 1. Parameters of case study. 
Continued

\begin{tabular}{ccc}
\hline Reactor length & $L$ & $0.5 \mathrm{~m}$ \\
Fluid velocity & $v$ & $0.5 \mathrm{~m} / \mathrm{s}$ \\
Value of $Z$ for uniform distribution & $Z_{o}$ & $4 \mathrm{~mol} / \mathrm{m}^{2}$ \\
Reactor diameter & $d$ & $0.3 \mathrm{~m}$ \\
\hline
\end{tabular}

\section{Discussion of Results}

Equations (8) to (16) were solved numerically [11] using expressions for $Z$ given in Figure 2 and model parameters listed in Table 1. Based on these results, the idea behind the non-uniform distribution can best be seen by looking at the concentration profiles of $A$ and $R$ along the reactor bed for the conventional uniform catalyst distribution, given in Figure 3 and Figure 4. By this unconventional distribution, the aim is to place the catalyst mostly in zones where the concentration of $A$ is high (to enhance the first reaction) and less in places where the concentration of $R$ is high (to inhibit the subsequent reactions).

The effect of change in catalyst distribution on the performance of the reactor (given in terms of the production rate of $R$, which is the desired product) is given in Figure 5. This figure shows the production rate of the desirable compound, $R$, over time for various non-uniform catalyst distributions, indicated by different values of $m$. The results show that the best production performance among these cases is achieved when $m=0$, which is for the case when catalyst distribution is linearly decreasing along the length of the reactor. The production rate for $R$ decreases as $m$ increases and is the lowest for $m=1$ where most of the catalyst is concentrated close to the outlet. This trend indicates the advantage of concentrating the placement of catalyst in the reactor zone where the concentration of $A$ is high.

The comparison of production rate of $R$ for conventional uniform distribution with the best of the non-uniform options studied here (corresponding to $m=0$, referred to as preferred distribution) can be seen in Figure 6. The results on the cumulative conversion of $A$, given by Figure 7, also confirm the enhancement of the reactor performance with the proposed non-uniform catalyst distribution.

Another key consideration in improving the performance and optimizing the design of the fixed-bed catalytic reactors is prolonging the life of catalyst and inhibiting processes that result in the loss of active sites due to various deactivation mechanisms. In many series reactions of the type studied here, a key deactivation mechanism is the ultimate formation of compounds in the sequence of reactions that would finally adsorb on catalytic sites and poison or decrease the catalytic activity. For example, in case of many hydrocarbon-processing reactions, a potential degradation reaction is the formation of heavy organic molecules that are attracted and adsorbed on the same sites-a process that destroys catalysts availability for the desirable reactions [5].

The best way to mitigate the wasting of catalyst and to preserve its activity and lifetime is to minimize its presence in locations where the concentration of $R$ is 


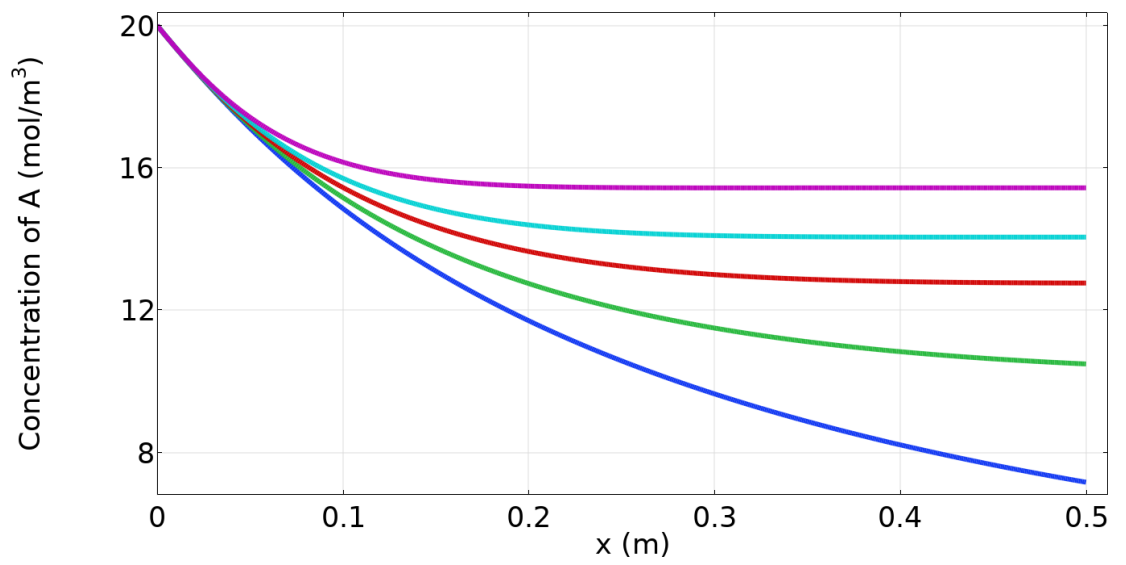

Figure 3. Concentration profile of $A$ with the uniform catalyst distribution: $30 \mathrm{~h}$ (purple), $20 \mathrm{~h}$ (light blue), $15 \mathrm{~h}$ (red), $10 \mathrm{~h}$ (green), and $5 \mathrm{~h}$ (blue).

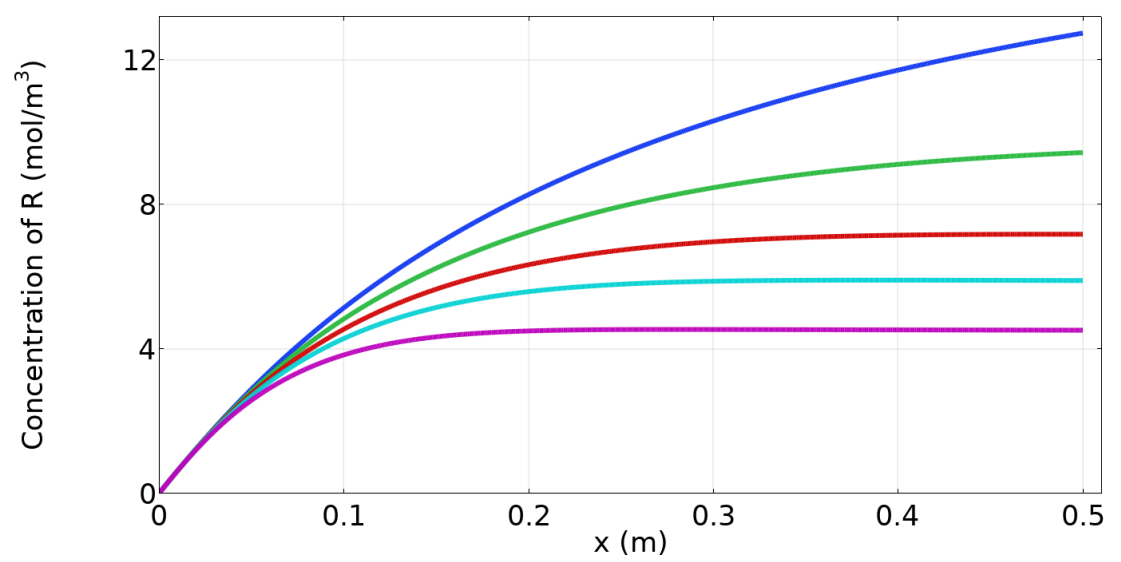

Figure 4. Concentration profile of $R$ with the uniform catalyst distribution: 5 h (blue), 10 $\mathrm{h}$ (green), $15 \mathrm{~h}$ (red), $20 \mathrm{~h}$ (light blue), and $30 \mathrm{~h}$ (purple).

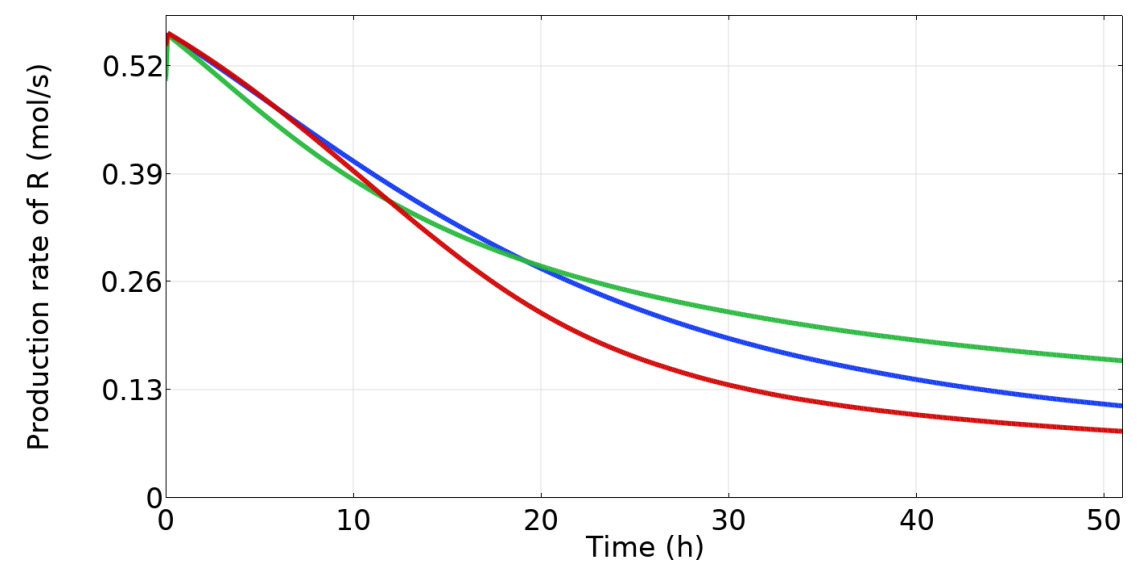

Figure 5. Production rate of $R$ for various non-uniform catalyst distributions: $m=0$ (green), $m=0.5$ (blue), and $m=1$ (red).

high, as previously shown in Figure 4 . The inhibition of the reactions that lead to the formation of the deactivating compound $P$ and the resulting loss of catalytic activity is also confirmed in Figure 8, where the total amount of deposited 


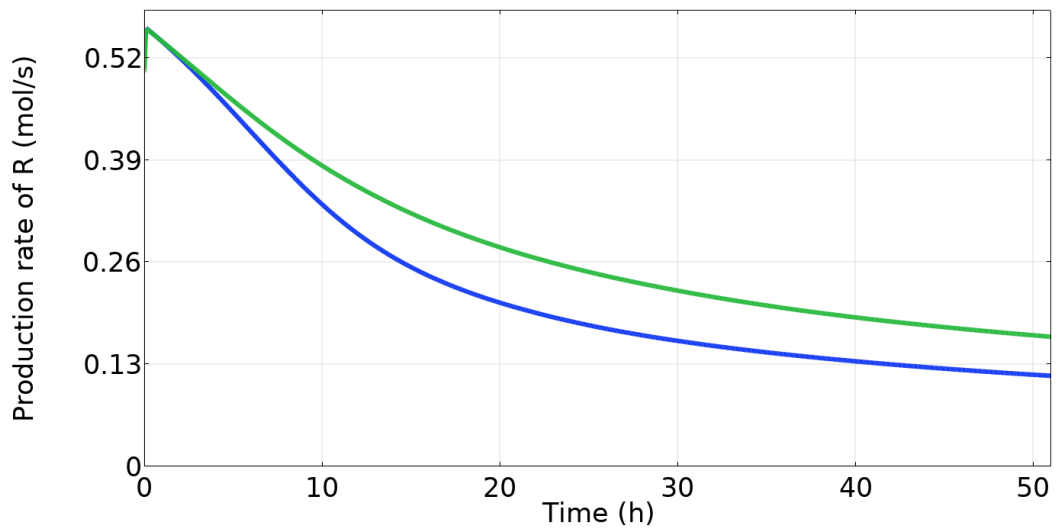

Figure 6. Comparison of the production rate of $R$ for uniform and preferred non-uniform $(m=0)$ catalyst distributions: non-uniform distribution $(m=0)$ (green), and uniform distribution (blue).

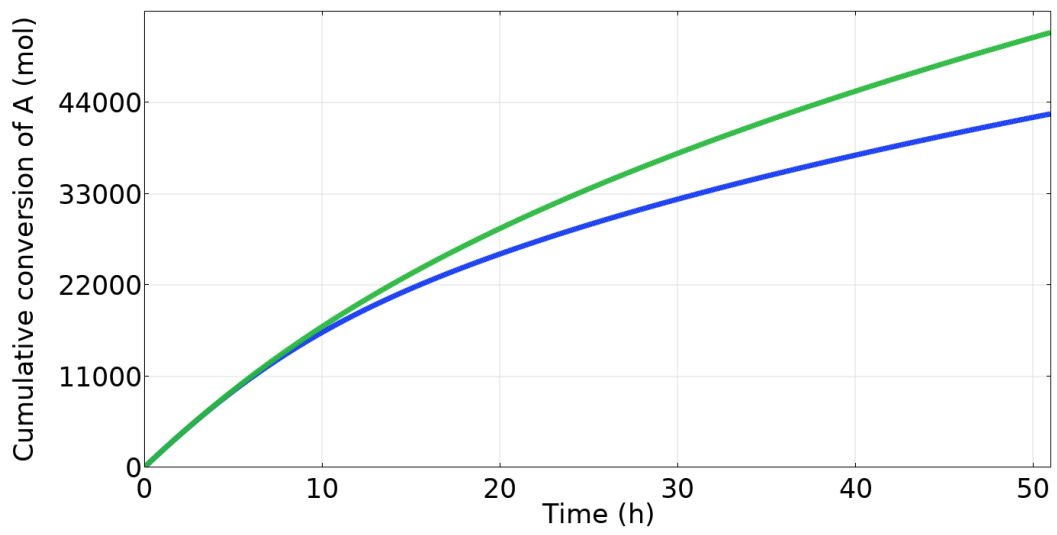

Figure 7. Comparison of the cumulative conversion of $A$ for uniform and preferred non-uniform $(m=0)$ catalyst distributions: non-uniform distribution $(m=0)$ (green), and uniform distribution (blue).

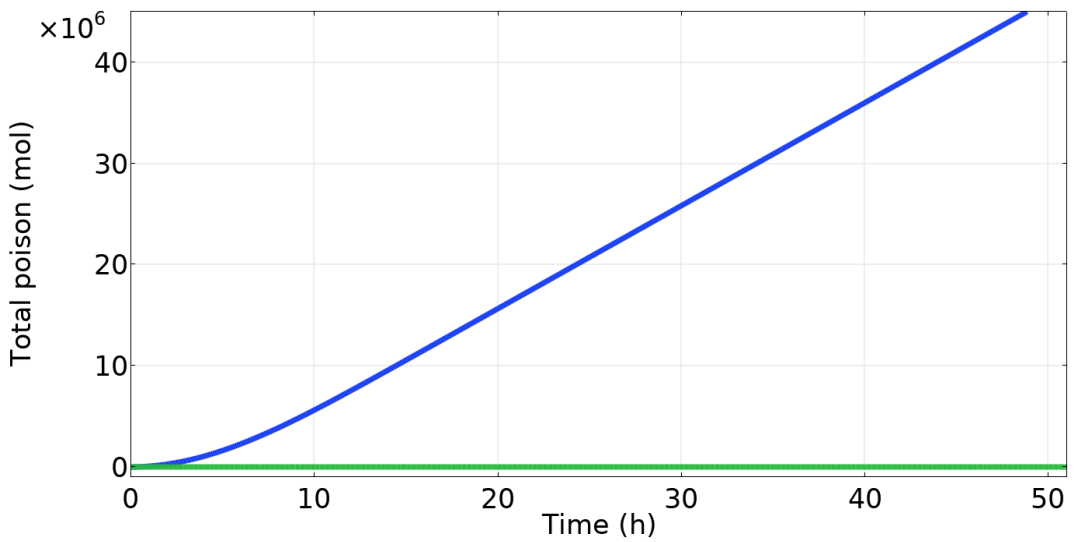

Figure 8. Comparison of the cumulative amounts of compound $P$ (total deactivated sites) in the reactor for uniform and preferred non-uniform $(m=0)$ catalyst distributions: uniform distribution (blue), and non-uniform distribution $(m=0)$ (green).

poison (deactivated sites) in the reactor is shown and compared for the conventional uniform and the proposed non-uniform catalyst distribution cases. 


\section{Conclusion}

The mathematical process modeling is shown to be valuable for optimization of catalyst distribution in typical fixed-bed chemical reactors. The comprehensive model developed in this study includes various modes of mass transport and chemical reactions as well as their complex interactions. To illustrate the application and the value of this model, the case of series reactions is considered which consists of a desirable intermediate compound followed by the chemical degradation of this compound if the process conditions are not optimized. The modeling shows that in such cases, which are common in practice, replacing the conventional uniform catalyst distribution with a novel non-uniform distribution will significantly improve the performance of the reactor and the production of the desirable compound. Various non-uniform options are considered and compared using the developed process model. The results show that for these series reactions, the preferred option is an unconventional approach where the catalyst loading is highest close to the inlet and decreases along the reactor bed. In addition to improving the production selectivity, the proposed distribution also prolongs the catalyst life. The model is versatile and can be used for both design of new systems as well as optimization of the operating conditions in existing reactors in a wide variety of reactor and reaction conditions. For the future work, further analysis of the deactivation process for other types of multiple reactions will be conducted and an optimization subroutine will be developed and added to the model for design and process tuning applications.

\section{Acknowledgements}

The support for this study was provided by NSF/SRC Engineering Research Center and its industrial members.

\section{Conflicts of Interest}

The authors declare no conflicts of interest regarding the publication of this paper.

\section{References}

[1] Nie, Y., Witt, P.M., Agarwal, A. and Biegler, L.T. (2013) Optimal Active Catalyst and Inert Distriubtion in Catalytic Packed Bed Reactors: ortho-Xylene Oxidation. Industrial \& Engineering Chemistry Research, 52, 15311-15320. https://dx.doi.org/10.1021/ie4005699

[2] Behm, R.J. and Jusys, Z. (2005) The Potential of Model Studies for the Understanding of Catalyst Poisoning and Temperature Effects in Polymer Electrolyte Fuel Cell Reactions. Journal of Power Sources, 154, 327-342. https://dx.doi.org/10.1016/j.jpowsour.2005.10.086

[3] Hamilton, C.A., Jackson, S.D., Kelly, G.J., Spence, R. and de Bruin, D. (2002) Competitive Reactions in Alkyne Hydrogenation. Applied Catalysis A: General, 237, 201-209. https://dx.doi.org/10.1016/S0926-860X(02)00332-0

[4] Yan, Y., Li, H.W., Maekawa, H. Miwa, K., Towata, S. and Orimo, S. (2011) Forma- 
tion of Intermediate Compound $\mathrm{Li}_{2} \mathrm{~B}_{12} \mathrm{H}_{12}$ during the Dehydrogenation Process of the $\mathrm{LiBH}_{4}-\mathrm{MgH}_{2}$ System. The Journal of Physical Chemistry C, 115, 19419-19423. https://dx.doi.org/10.1021/jp205450c

[5] Mann, R., El-Kady, F.Y.A. and Marzin, R. (1985) Catalyst Deactivation by Fouling: a Wedge-Layering Analysis of the Consecutive Reaction. Chemical Engineering Science, 40, 249-257. https://dx.doi.org/10.1016/0009-2509(85)80064-6

[6] Barbier, J. (1986) Deactivation of Reforming Catalyst by Coking-A Review. Applied Catalysis, 23, 225-243. https://dx.doi.org/10.1016/S0166-9834(00)81294-4

[7] Gray, M.R. and McCaffrey, W.C. (2002) Role of Chain Reactions and Olefin Formation in Cracking, Hydroconversion, and Coking of Petroleum and Bitumen Fractions. Energy \& Fuels, 16, 756-766. https://dx.doi.org/10.1021/ef010243s

[8] Frank, B., Zhang, J., Blume, R., Schlögl, R. and Sheng Su, D. (2009) Heteroatoms Increase the Selectivity in Oxidative Dehydrogenation Reactions on Nanocarbons. Angewandte Chemie, 48, 6913-6917. https://dx.doi.org/10.1002/anie.200901826

[9] Sada, E. and Wen, C.Y. (1967) Effect of Catalyst Poisoning on the Overall Selectivity and Activity. Chemical Engineering Science, 22, 559-571.

https://dx.doi.org/10.1016/0009-2509(67)80039-3

[10] Bird, R.B. (1960) Transport Phenomena. Wiley, New York, 554-559.

[11] COMSOL Multiphysics 5.5 [Computer Software] (2019).

https://www.comsol.com 


\section{Nomenclature}

\begin{tabular}{|c|c|}
\hline a & Ratio of the packing surface area to the reactor volume $\left(\mathrm{m}^{-1}\right)$ \\
\hline$A_{(g)}$ & Feed compound \\
\hline$C_{A}$ & Concentration of species $A\left(\mathrm{~mol} / \mathrm{m}^{3}\right)$ \\
\hline$C_{i}$ & Concentration of species $i\left(\mathrm{~mol} / \mathrm{m}^{3}\right)$ \\
\hline$C_{i, i n}$ & Initial concentration of species $i$ \\
\hline$C_{i, o}$ & Inlet concentration of species $i\left(\mathrm{~mol} / \mathrm{m}^{3}\right)$ \\
\hline$C_{i, \text { out }}$ & Concentration of species $i$ at the outlet $\left(\mathrm{mol} / \mathrm{m}^{3}\right)$ \\
\hline$C_{R}$ & Concentration of species $R\left(\mathrm{~mol} / \mathrm{m}^{3}\right)$ \\
\hline$C_{S}$ & Concentration of species $S\left(\mathrm{~mol} / \mathrm{m}^{3}\right)$ \\
\hline$C_{P}$ & Surface concentration of deactivated sites $\left(\mathrm{mol} / \mathrm{m}^{2}\right)$ \\
\hline$d$ & Reactor diameter $(\mathrm{m})$ \\
\hline$D_{A}$ & Dispersion coefficient for compound $A\left(\mathrm{~m}^{2} / \mathrm{s}\right)$ \\
\hline$D_{i}$ & Dispersion coefficient for compound $i\left(\mathrm{~m}^{2} / \mathrm{s}\right)$ \\
\hline$D_{R}$ & Dispersion coefficient for compound $R\left(\mathrm{~m}^{2} / \mathrm{s}\right)$ \\
\hline$D_{S}$ & Dispersion coefficient for compound $S\left(\mathrm{~m}^{2} / \mathrm{s}\right)$ \\
\hline$i$ & Species $A, R, S$, or $P$. \\
\hline$k_{1}$ & Reaction rate coefficient of the first forward reaction $\left(\mathrm{m}^{2} \cdot \mathrm{s}^{-1} \cdot \mathrm{mol}^{-1}\right)$ \\
\hline$k_{1 \mathrm{r}}$ & Reaction rate coefficient of the first reverse reaction $\left(\mathrm{m}^{2} \cdot \mathrm{s}^{-1} \cdot \mathrm{mol}^{-1}\right)$ \\
\hline$k_{2}$ & Reaction rate coefficient of the second forward reaction $\left(\mathrm{s}^{-1}\right)$ \\
\hline$k_{2 \mathrm{r}}$ & Reaction rate coefficient of the second reverse reaction $\left(\mathrm{s}^{-1}\right)$ \\
\hline$k_{3}$ & Reaction rate coefficient of the third forward reaction $\left(\mathrm{m}^{2} \cdot \mathrm{s}^{-1} \cdot \mathrm{mol}^{-1}\right)$ \\
\hline$k_{3 \mathrm{r}}$ & Reaction rate coefficient of the third reverse reaction $\left(\mathrm{s}^{-1}\right)$ \\
\hline$L$ & Reactor length (m) \\
\hline$m$ & Parameter in catalyst distribution equation \\
\hline$P_{(s)}$ & Undesirable deactivating end product \\
\hline$R_{(g)}$ & Desirable product \\
\hline$S_{(g)}$ & Undesirable product \\
\hline$t$ & Time (s) \\
\hline$v$ & Fluid velocity $(\mathrm{m} / \mathrm{s})$ \\
\hline$x$ & Location along the packed bed $(\mathrm{m})$ \\
\hline$Z$ & Surface concentration of catalytic sites $\left(\mathrm{mol} / \mathrm{m}^{2}\right)$ \\
\hline$Z_{0}$ & Value of $\mathrm{Z}$ for uniform catalyst distribution $\left(\mathrm{mol} / \mathrm{m}^{2}\right)$ \\
\hline
\end{tabular}

